\title{
Correction to: Inhibitory effects of tea polyphenols by targeting cyclooxygenase-2 through regulation of nuclear factor kappa B, Akt and $\mathrm{p} 53$ in rat mammary tumors
}

\author{
Preeti Roy ${ }^{1}$. Jasmine George ${ }^{1} \cdot$ Smita Srivastava ${ }^{1} \cdot$ Shilpa Tyagi $^{1} \cdot$ Yogeshwer Shukla $^{1}$
}

Published online: 7 August 2019

(C) Springer Science+Business Media, LLC, part of Springer Nature 2019

Correction to: Investigational New Drugs 29 (2011) 225-31

https://doi.org/10.1007/s10637-009-9349-y

The authors regret to inform that there were unknowing errors in figures. The corrected images are given below. These figures are not affecting the results and conclusion of the manuscript. Hence, the text in original paper remains unchanged.

The authors would like to apologise for any inconvenience caused.

Publisher's note Springer Nature remains neutral with regard to jurisdictional claims in published maps and institutional affiliations.

The online version of the original article can be found at https://doi.org/ 10.1007/s10637-009-9349-y

Yogeshwer Shukla

yshukla@iitr.res.in

1 Proteomics Laboratory, Indian Institute of Toxicology Research, CSIR, Mahatma Gandhi Marg, Lucknow 226001, India 
Fig. 3 Western blots showing the effect of GTP and BTP on a NF$\kappa \mathrm{B}, \mathbf{b} \mathrm{Akt}$, c Cox-2, d Wild typep53, e Mutant- p53 and $\mathbf{f} \beta$-actin in mouse mammary tumors in different groups. Lanes: (a) Control, (b) (0.1\%) GTP, (c) $(0.1 \%)$ BTP, (d) DMBA, (e) $(0.1 \%)$ GTP + DMBA, (f) $(0.1 \%)$ BTP + DMBA. Equal loading of the samples was evaluated by reprobing the membranes with $\beta$ actin antibody. The bands shown here are from a representative experiment repeated three times with similar results. All the data were significant at $p<0.05$

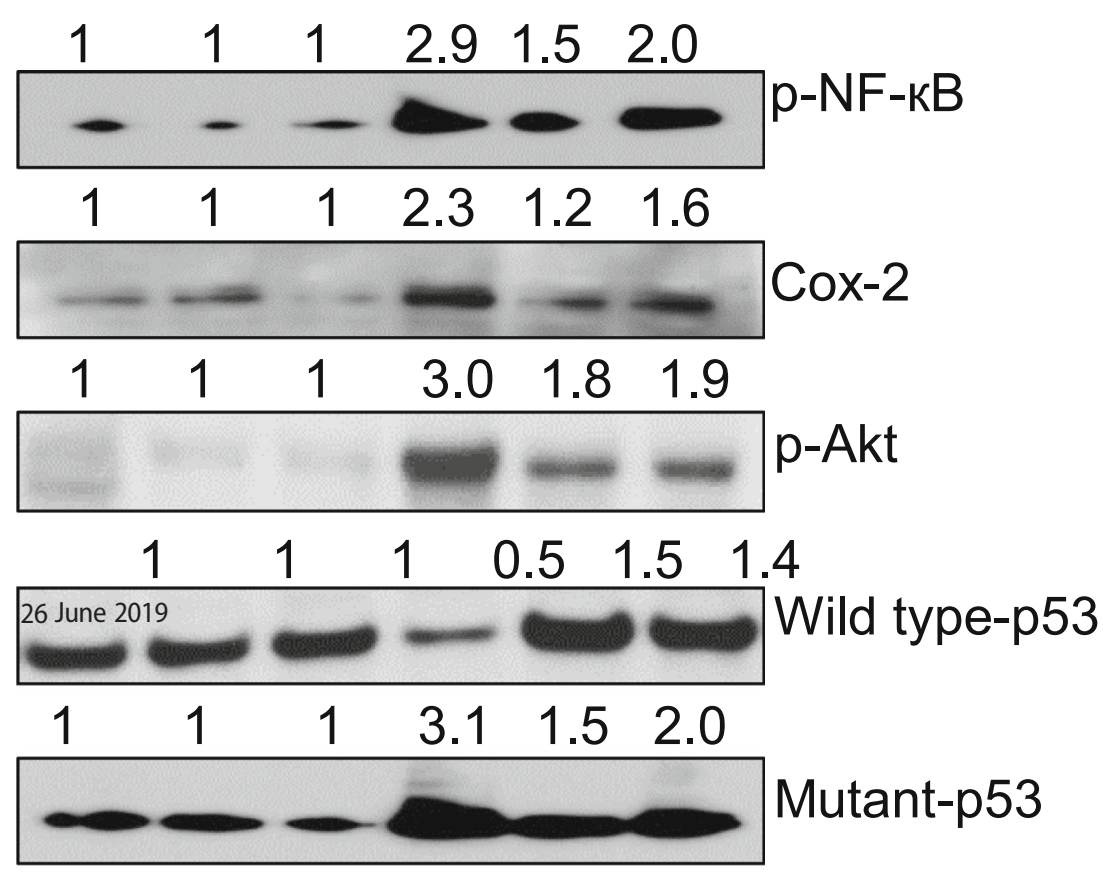

$\beta$-actin 